\title{
Finite Element Analysis of the effect of High Tibial Osteotomy correction angle on articular cartilage loading
}

Zahra Trad ${ }^{1}$, Abdelwahed Barkaoui ${ }^{1}$, Moez Chafra ${ }^{2}$, João Manuel R. S. Tavares ${ }^{3}$

\begin{abstract}
${ }^{1}$ Université de Tunis El Manar, Ecole Nationale d'Ingénieurs de Tunis, LR-11-ES19 Laboratoire de Mécanique Appliquée et Ingénierie (LR-MAI), 1002, Tunis, TUNISIE, email: tradzahra@outlook.com, abdelwahed.barkaoui@ipeiem.utm.tn
\end{abstract}

${ }^{2}$ Université de Carthage, Ecole Polytechnique de Tunisie, Laboratoire de Systèmes et de Mécanique Appliquée (Lasmap-EPT), 2078, La Marsa, TUNISIE, email: chafra moez@yahoo.fr

${ }^{3}$ Instituto de Ciência e Inovação em Engenharia Mecânica e Engenharia Industrial, Departamento de Engenharia Mecânica, Faculdade de Engenharia, Universidade do Porto, Porto, PORTUGAL, e-mail: tavares@fe.up.pt

Corresponding author:

Prof. João Manuel R. S. Tavares

Faculdade de Engenharia da Universidade do Porto

Departamento de Engenharia Mecânica

Rua Dr. Roberto Frias, s/n, 4200-465 Porto, PORTUGAL

Phone: +351 22508 1487, Fax: +351 225081445

e-mail: tavares@fe.up.pt, url:www.fe.up.pt/ tavares 


\title{
Finite Element Analysis of the effect of High Tibial Osteotomy correction angle on articular cartilage loading
}

\begin{abstract}
Osteoarthritis (OA) is a globally common disease that imposes a considerable ongoing health and economic burden on the socioeconomic system. As more and more biomechanical factors have been explored, malalignment of the lower limb has been found to influence the load distribution across the articular surface of the knee joint substantially. In this work, a three-dimensional finite element analysis was carried out to investigate the effect of varying the High Tibial Osteotomy (HTO) correction angle on the stress distribution in both compartments of the human knee joint. Thereafter, determine the optimal correction angle to achieve a balanced loading between these two compartments. The developed finite element model was validated against experimental and numerical results. The findings of this work suggest that by changing the correction angle from 0 to $10^{\circ}$ valgus, HTO shifted the mechanical load from the affected medial compartment to the lateral compartment with intact cartilage. The Von Mises and the shear stresses decreased in the medial compartment and increased in the lateral compartment. Moreover, a balanced stress distribution between the two compartments as well as the desired alignment were achieved under a valgus hypercorrection of $4.5^{\circ}$ that significantly unloads the medial compartment, loads the lateral compartment and arrests the progression of OA. After comparing the achieved results against the ones of previously studies that explored the effects of the HTO correction angle on either clinical outcomes or biomechanical outcomes, one can conclude that the findings of this study agree well with the related clinical data and recommendations found in the literature.
\end{abstract}

Keywords: Knee Biomechanics, Finite Element Analysis, Stress distribution, Von Mises, Osteoarthritis. 


\section{Introduction}

The knee is the most vulnerable joint in human body because it bears enormous weight and pressure loads while providing flexible movement. The bone epiphyses of the knee joint are covered with cartilage, which supports the majority of the loading. Because of its mechanical properties and location in the knee joint, cartilage breaks down and subsequently degenerates, causing pain and stiffening during normal movements. In fact, the malalignment of lower limb substantially influences the load distribution across the articular surface of the knee joint (1), which is therefore considered as a critical risk factor for osteoarthritis (OA) progression. Concerning the knee afflicted by medial compartment OA, a lateral closing-wedge High Tibial Osteotomy (HTO) can be an effective answer to conservative management of interrupting the disease progression (2-4). The aim of an HTO is to shift the load from the affected area to other areas with intact cartilage by correcting the Hip-Knee-Ankle (HKA) angle thereby providing considerable advantages over conventionally used total knee replacement by well preserving the biological knee structures. However, the achieving of the appropriate alignment is a critical determinant of success for an HTO to treat medial compartment knee OA.

Actually, clinical studies available in the literature lack consensus on the ideal alignment to maximize the osteotomy survival and post-operative knee function. The recommended optimal alignment following HTO varies significantly among different authors; some of them even present contradictory results. Sprenger and Doerzbacher (5) assessed the correlation between various clinical and radiographic factors and the long-term results after HTO performed in 66 patients suffered from medial compartment OA. In their study, the radiographic valgus angle ranged between $8^{\circ}$ and $16^{\circ}$ at one year from surgery had the most significant positive effect on survivorship for all end points compared with the other parameters. Similarly, the retrospective study of Aglietti et al. (6) treated 120 Closing Wedge High Tibial Osteotomies for varus gonarthrosis. Only 61 knees were left for clinical and radiographic evaluation. Satisfactorily results were correlated to valgus alignment at consolidation between $8^{\circ}$ and $15^{\circ}$ at an average follow-up of 15 years. The best long results in the study of Valenti et al. (7) were divided into 3 groups in relations to the correction achieved. The valgus angle was more than $3^{\circ}$ and less than $8^{\circ}$ in the group of patients with standard correction and it was more than $8^{\circ}$ in the group of patients with overcorrection. Indeed, Hernigou et al. (8) evaluated the results of 93 knees operated by Opening Wedge HTO after a mean length of follow-up of 11.5 years. The best outcomes were obtained in the twenty knees that had a HKA angle ranged between $183^{\circ}$ 
to $186^{\circ}$ (from $3^{\circ}$ to $6^{\circ}$ of valgus). Ivarsson, Myrnerts \& Gillquist (9) reviewed 99 knees after HTO and they reported that a mean angulation of $3^{\circ}$ to $7^{\circ}$ of valgus significantly ensures a good period of relief of symptoms after osteotomy. However, the study of Benzakour et al. (10) revealed that an average of $5^{\circ}$ mechanical valgus at the time of osteotomy ensures a good patient recovery for at least ten years. Therefore, various suggestions have been advanced to define this angle. Nevertheless, the determination of the ideal HTO alignment is still controversial.

Another research line that is attaining increasing attention is based on biomechanical studies in order to optimize the correction angle. Mina et al. (11) attempted to directly relate the correction angle to the contact loading pattern of the knee joint by using electronic pressure sensor inserted into the cartilage of cadaveric knee specimen under a specific mechanical testing system simulating the functional activity of the knee joint. Based on achieving equal stress distribution between the medial and lateral compartments, which is considered most closely approximating idealised physiologic loading, they recommended an alignment of $0^{\circ}$ to $4^{\circ}$ of valgus. Briem et al. (12) investigated the effect of the degree of alignment angle after open wedge HTO surgery on joint moments, muscle co-contraction and self-reported functional outcome. From their study, the authors found that the mean mechanical axis angle was $185^{\circ}\left(5^{\circ}\right.$ of valgus) and the mean weight-bearing line ratio was $73.4 \%$ at 1 year after surgery.

Several research works (13-42) investigated the biomechanics of the human knee joint in order to achieve new insights useful for the clinical area. Some other studies reviewed the biomechanical behavior of the knee joint and evaluated the use of finite element method in modeling this joint(43-47). In the study of Fernandes et al.(48), a 3D finite element analysis (FEA) model was developed to study the biomechanical behavior of the knee joint after an ACL rupture and to compare the biomechanical changes induced by an isotropic Marlow and anisotropic Holzapfel-Gasser-Ogden (HGO) hyperelastic constitutive models when modeling the knee ligaments. The bones were defined as rigid bodies, and the articular cartilage and the menisci were modeled as linear elastic isotropic materials. The findings of this study revealed that the HGO model presents more accurate results since it has better reproduced the mechanical behavior of the ligaments. Moreover, the ACL rupture led to a clear increase in the knee laxity in more than one degree of freedom that induced several drastic kinematic changes, which have a great impact on the overall biomechanics of the entire knee structure.

Peña et al. conducted a series of FEA studies (49-54), using the same magnetic resonance imaging (MRI) based model, to investigate the stress and strain behaviors in the soft tissues of a healthy human knee joint and after meniscectomy. In the study of meniscectomy (54), the minimal principal stresses corresponding to a compressive load at full extension were 
obtained for the posterior region of the medial meniscus and the corresponding region of the cartilage. Under an axial compressive loading at the femur, the maximal contact stress in the articular cartilage after meniscectomy was about twice of that in a healthy joint.

Another study conducted by Halonen et al. (55) characterized the effects of collagen fibrill orientations, collagen distribution and proteoglycan (PG) distribution on the knee joint stresses and strains in cartilage during human gait cycle as well as at mechanical equilibrium. A 3D FE knee joint model was created including only the femoral and tibial cartilages and the menisci. The articular cartilage was assumed to behave as Fibril reinforced poroviscoelastic (FRPVE) material and the menisci were modeled as elastic transversely isotropic material. The findings of this study revealed that the collagen fibril orientation in cartilage substantially affects the depth-wise tissue strains and stresses during dynamic and static loading of a joint. Moreover, the mechanical behavior of the tibial articular cartilage in the knee joint is minimally affected by the fibril volume density distribution. Finally, the depth-dependent PG content substantially affects the cartilage strains and stresses at the standing position of the joint. An acceptable approach for analyzing the loading patterns in cartilage during the gait cycle was developed using the results obtained by the authors. These results allowed the creation of the knee joint model that incorporates the arcade-like collagen orientation in cartilage. However, an important role is assumed by the depth-wise PG distribution in the simulations of equilibrium loading.

However, there is a lack of FEA based studies investigating the effect of varying knee alignment on the stress distribution at soft tissues. These studies could have the potential of providing a standardized HTO alignment, notably for the optimization of the value of the correction angle. Therefore, the present article focuses on developing a 3D FE knee joint model to predict the local stress distribution at the tibiofemoral joint and investigate the effect of varying the HTO correction angle on the stress distributions at the knee cartilages. Finally, the FEA results can be used to determine the optimal correction angle that strongly affects the HTO treatment success.

\section{Material and methods}

\section{Knee joint geometry}

The human knee has complicated geometry, and modelling of this joint can be notably challenging. The 3D model of the right lower limb studied in this work was extracted from a 3D anonymous human skeleton obtained from the ZBrush 4R7 (Pixologic, Inc., USA) software. Then, 
it was exported to SolidWorks (SolidWorks Corporation, USA) where scaling was performed to achieve on the one hand, the physiological dimensioning of the lower limb, and on the other hand, to perform the proper adjustment to the knee joint to be used as reference for the simulation of different corrections of the HTO. The anterior, posterior and lateral weight-bearing Xray views were used to assess the knee joint in the normal anatomical position and to better comprehend the joint space when the patient is in standing position.

In a third step, the surface covering the four bones constituting this joint, i.e., femur, tibia, fibula and patella, was added. Then, we have taken under account the design of the articular cartilage at the distal epiphysis of the femur, the proximal epiphysis of the tibia and the posterior epiphysis of the patella. Because it is a simulation model, we assumed that the articular cartilage has a constant thickness of $4 \mathrm{~mm}$, which is in accordance with the study of Guess et al. (56). Finally, the design of medial and lateral menisci has been accomplished, Figure 1. Both menisci and articular cartilage were modeled using SolidWorks and the arthroscopic knee images in order to respect the anatomy under study.

$<$ Figure 1 should be around here $>$

In order to facilitate the modelling of the joint, the ligament system providing the mechanical connection between the femur and the tibia was modeled using axial springs in Abaqus (Dassault Systemes, France).

Once the solid model had been generated, the mesh was built in Abaqus. All bones, cartilage and menisci were discretized into 10-node tri-linear tetrahedral elements. Tetrahedral elements were chosen over hexahedral elements attributable due to its great flexibility in meshing complex curved geometry. Then, in order to this study brings new understand about the behavior of soft tissue, a refined mesh was used in the articular cartilage and meniscus, Figure 2.

$<$ Figure 2 should be around here $>$

\section{Material properties}

The material properties were assigned according to pertinent literature. Several studies (4854,57 ) have assumed that the femur and tibia as rigid bodies because of their relatively high density and Young's modules compared to the cartilage and menisci in the knee joint. On the other hand, previous FEA studies $(56,58-62)$ did not take into account the difference between cancellous and cortical bone and considered the whole bony structure of the knee joint as cortical bone. For 
example, Guess et al. ${ }^{11}$ developed dynamic 3D anatomical knee joint models with sufficient computational competence for human movement simulation. In their study, the tibia was considered as a rigid body and the femur assumed to be a linear elastic isotropic material with a Young's modulus of $20 \mathrm{GPa}$ and a Poison's ratio of 0.2 . Moreover, in the study conducted by Zheng et al. ${ }^{15}$, where the influence of material properties on menisci responses was investigated, the concellous bone was neglected and the femur, the tibia and the fibula were modeled as linear elastic isotropic material. In this study, the femur, tibia, patella and fibula were assumed to be a linear elastic and isotropic material with Young's Modulus of $20 \mathrm{GPa}$, Poisson's ratio of 0.3 and density of $1600 \mathrm{~kg} / \mathrm{m}^{3}(56,63-66)$.

Despite being a hydrated tissue, the loading time of interest corresponds to that of a single leg stance and the viscoelastic time constant of cartilage approaches $1500 \mathrm{~s}$, the articular cartilage is considered as a single-phase isotropic linear and elastic material, with elastic modulus of $5 \mathrm{MPa}$, Poisson's ratio of 0.46 and density of $1000 \mathrm{~kg} / \mathrm{m}^{3}(18,19,49,52,54,64,67-73)$. The same approach has been adopted in many other studies $(32,49,63,68,74-81)$, and can be accurate enough to predict short-term cartilage response as indicated by Donzelli et al. (33), who proved that there are no significant changes in the cartilage contact response shortly after loading. For the same reason, menisci were also specified as a single-phase linear isotropic and elastic material with the following average properties: elastic modulus of $59 \mathrm{MPa}$, Poisson's ratio of 0.49 and density of $1100 \mathrm{~kg} / \mathrm{m}^{3}(49,50,52-54,64,81,82)$.

On modelling ligaments, two important assumptions were made: First, no difference in the material behavior between the ligament body and its insertion can be noticed. Second, material characteristics depending on time, such as viscoelasticity, creep and relaxation, can be neglected (41), again due to the high ratio between the viscoelastic time constant of the material and the loading time of interest in this study. We used therefore, spring elements that connect the femur to the tibia. Each ligament bundle consisted of two springs with a total stiffness of $1600 \mathrm{~N} / \mathrm{mm}$ or $800 \mathrm{~N} / \mathrm{mm}$ per spring (32).

\section{Loads and boundary conditions}

For a static analysis in Abaqus, small sliding surface interactions were defined between lateral meniscus-femoral cartilage, lateral meniscus-tibial cartilage, medial meniscus-femoral cartilage and medial meniscus-tibial cartilage pairs, femoral cartilage and tibial cartilage on both the lateral and medial sides. The contact pressure-clearance relationship used to define the interaction between these surfaces was a 'hard contact' model, which means that no penetration was allowed of the nodes from one surface into the other surface and no transfer of tensile stress 
was allowed across the interface (68). An augmented Lagrangian algorithm was adopted to simulate the contacts between femoral cartilage, tibial cartilage and menisci with frictionless behavior assumed to mimic the lubrication in the knee joint.

Tie constraints were also generated between femur and cartilage, tibia and both medial and lateral cartilage, patella and cartilage, fibula and tibia and the four horns of menisci and the tibial plateau. A slave and master surfaces were defined for each contact pair set. Each slave node was checked for penetration into its corresponding master surface. During simulation, the proximal surface of the femur was considered to be fixed in all degrees of freedom, whereas the tibia and fibula were free in all degrees of freedom, Figure 3.

$<$ Figure 3 should be around here $>$

Finally, a single axial force was applied to obtain the stress distribution at the articular cartilage for the different correction angles adopted in this study. Most of the FEA studies on knee joint only concerned the stress distribution at both cartilage and menisci under pure axial loading $(56,62,83)$. In this study, we supposed that the subject under analysis had a weight of $125 \mathrm{~kg}$, and a single axial force approximately to the body weight of $1250 \mathrm{~N}$ was applied at the coupling point of the distal surfaces of the tibia and the fibula. However, a little exception was done in order to compare the developed knee model with those available in the literature. A single axial force of $740 \mathrm{~N}$ was applied on the femur to obtain the stress distribution at the menisci and cartilage, which can be compared against the stress values obtained in those studies. Nevertheless, it should be noted that most of the FEA studies on knee joints are only concerned with the stress distribution at both cartilage and menisci under pure axial loading.

\section{HTO modeling}

A Closed-Wedge High Tibial varus Osteotomy (CWHTO) is a very specific surgical technique that removes a part of the bone in the medial section of the knee joint at the top of the tibia to restore the stability of the knee. The accuracy of the correction depends on the surgical technique because the lack of accuracy and precision when cutting the wedge of the bone affects the quality of the patient's recovery. Prior to the modeling of the osteotomy, we generated a varus knee model from the healthy knee model. This was made by creating a bone deflection forming an inclination angle $\alpha=12^{\circ}$ between the mechanical axis of the femur and the mechanical axis of the tibia. Therefore, as shown in Figure 4, the mechanical axis of the tibia of the healthy knee joint was shifted medially to produce a varus knee model with a HKA 
angle of $168^{\circ}$. Since this model was not obtained from a pathologic knee, it does not include the thinned cartilage nor sclerosed bone.

$<$ Figure 4 should be around here $>$

The next step was the planning of the operative steps of the HTO for each value of the correction angle $(\gamma)$, which represents the sum of the hypercorrection $(\beta)$ and the inclination angle $(\alpha)$. Indeed, the hypercorrection in valgus is necessary during osteotomy. It is confirmed by most of the results published in the literature $(7,8,84-87)$ that its value is within a range of 0 to $10^{\circ}$. Therefore, seven values of the hypercorrections $\beta=\left\{0^{\circ}, 3^{\circ}, 4^{\circ}, 4.5^{\circ}, 5^{\circ}, 6^{\circ}, 10^{\circ}\right\}$ were chosen in this study in order to investigate the effect of varying the correction angle on the stress distribution in the knee joint and therefore, to determine the optimal angle that limits the degeneration of the articular cartilage. Figure 5 summarizes all the angles taken into account when modeling the CWHTO.

$<$ Figure 5 should be around here $>$

Following the rules of the operating technique of the HTO, the osteotomy line should be distant from the tibial joint line of $d=25 \mathrm{~mm}$, Figure 5 . Once the geometry is defined, the wedge of bone is removed, the osteotomy is closed, and the cut surfaces of the tibia are held together, Figure 6. As this highlights the effect of the valgisation angle on the stress distribution in the articular cartilage, it was assumed that the period of consolidation after surgery is accomplished and that the plate and screws used during the closure of the osteotomy are removed since this exclusion optimizes the results.

$<$ Figure 6 should be around here $>$

The last step was the export of the built models to Abaqus to numerically simulate each case and study the stress distribution in the knee joint after the correction of the femorotibial angle. The same load and boundary conditions were assigned to all the models. 


\section{Results}

\section{Validation of intact knee model}

In this work, under a $740 \mathrm{~N}$ compressive load, the lateral and medial compartment carried 42.2 and $57.8 \%$ of the total load, respectively, and the menisci transferred about $68 \%$ of the total load.

The highest contact pressure took place in the posterior region of the medial meniscus, with a maximum of $8.7 \mathrm{MPa}$, and in the anterior horn of the lateral meniscus, with a maximum of 6.4 $\mathrm{MPa}$. Basically, these locations corresponded to the contact zones between the femoral condyles and the menisci, and the obtained values were slightly similar to those obtained experimentally by Walker \& Erkiuan (88). The maximum Von Mises stress in articular cartilages were obtained to see overall stress distribution. Hence, our results revealed that the maximum Von Mises stress in the femoral cartilage, medial tibial cartilage and lateral tibial cartilage were equal to $1.75,2.65$ and $1.93 \mathrm{MPa}$, respectively.

Furthermore, this study was also developed taking into account clinical real cases. Hence, Figure 7 shows a human knee suffering from a varus, and with the cartilage of the medial condyle damaged, which was also addressed in this study.

$<$ Figure 7 should be around here $>$

\section{Effect of the correction angle on the stress redistribution}

The findings of this study showed that the variation of the degree of the HTO correction from 0 to $10^{\circ}$ valgus (shifting the loading axis laterally), had effectively decreased the medial compartment stresses and increased the lateral compartment stresses.

As shown in Figure 8, the maximum Von Mises stress decreased from 11.04 to $5.58 \mathrm{MPa}$ (50\% reduction) in the medial tibial cartilage and from 7.77 to $5.1 \mathrm{MPa}$ (35\% reduction) in the medial femoral cartilage. While, it increased in the lateral tibial cartilage from 4.45 to $6.85 \mathrm{MPa}$ (54\% increase) and from 3.6 to $6.3 \mathrm{MPa}(75 \%$ increase) in the lateral femoral cartilage.

Observing Figure 9, one can realize that the maximum shear stress was calculated decreasing in the medial dimensions of femoral and tibial cartilage, which is a reduction from 7.37 to $5.57 \mathrm{MPa}$ (33\% reduction) and from 8.21 to $4.85 \mathrm{MPa}$ (41\% reduction), respectively. At the same time, the maximum shear stress for the lateral femoral and tibial cartilage can be observed to increase from 4.83 to $6.86 \mathrm{MPa}$ ( $42 \%$ increase) and from 4.4 to $6.71 \mathrm{MPa}(53 \%$ increase), respectively, when the knee alignment varied from 0 to $10^{\circ}$ valgus. 
$<$ Figures 8 and 9 should be around here $>$

As shown in Figures 9 and 10, for a correction angle of $16.5^{\circ}$, the medial compartment supports $51 \%$ and the lateral compartment supports $49 \%$ of the total load. Thereby allowing asserting that a balanced stress distribution between two compartments was achieved when the tibia was cut by a correction angle of $16.5^{\circ}$.

\section{Correction angle emphasis}

In order to better investigate the effect of this correction degree of HTO $\left(\gamma=16.5^{\circ}\right)$ on the stress distribution across both the compartments, the range of the maximum stress to minimum stress had been set constant for all models and the same range of stress legend was adopted for each component. Therefore, the stress distribution pattern between the healthy knee joint model and the per/post-operative knee joint models becomes easily comparable. Also, in the related figures, the blue region indicates the higher Von Mises stresses whilst the red region indicates the lower Von Mises stresses.

The Von Mises stresses distributions obtained for the three models are shown in Figure 10. In the case of a varus knee, a high stress concentration was noticed in the posterior region of the lateral tibial cartilage and in the anterior region of the femoral cartilage and the lateral tibial cartilage. However, the trend of decrease in the Von Mises stress concentration on the medial and lateral side was clearly observed after shifting the loading axis laterally. Yet, it becomes relatively similar to that in the healthy knee joint.

$<$ Figure 10 should be around here $>$

Once more, the trend of decrease in the shear stress concentration on the medial side and subsequent increase in the stress concentration in the lateral side after shifting the loading axis laterally were observed, Table 1. The maximum shear stress decreased in the medial femoral cartilage and in the medial tibial cartilage from 8.67 to $5.76 \mathrm{MPa}$ and from 12.21 to $6.01 \mathrm{MPa}$, respectively. While, the maximum shear stress increased in the lateral femoral cartilage and in the lateral tibial cartilage from 4.27 to $5.67 \mathrm{MPa}$ and from 4.8 to $5.6 \mathrm{MPa}$, respectively.

$<$ Table 1 should be around here $>$ 


\section{Discussion}

The motivation for this work was the development of a 3D FE knee joint model that efficiently simulate the stress distributions in articular cartilages when varying the HTO correction angle. The underlying main goal was to determine the optimal correction angle that provides a balanced stress distribution between the two compartments.

One key finding of this study was that the model was successfully validated against experimental and numerical results from the literature $(32,49,50,64,83,89-93)$. Regarding the geometric accuracy, under a single compressive force of $740 \mathrm{~N}$, the load distribution values in our model were very close to the ones reported in the literature. In the study of Zhu et al. (90), the lateral and medial compartment carried 44.9 and $55.8 \%$ of the total load, respectively, under a compressive load of $1000 \mathrm{~N}$ (respectively, 42.2 and 57.8\% in this study). The menisci transferred about $69 \%$ of the total load (68\% in this study). The little observed discrepancy is a result of the different loads applied to the models.

A similarity in contact pressure was found between our model and results reported in the literature. In the previous work of Pena et al. (49), an axial compressive load of $1150 \mathrm{~N}$ was applied on a FE model of knee joint. The bone was considered as rigid body, cartilages and menisci behaved as a linear elastic and isotropic material, and ligaments were modelled as hyperelastic and isotropic. In their study, the maximal contact pressure appeared in the posterior region of the medial meniscus with average value of $2.9 \mathrm{MPa}$ and in the anterior horn of the lateral meniscus with average value of $1.45 \mathrm{MPa}$. The contact pressure was slightly higher in our study, probably, due to the difference between the subjects modelled; mainly, the difference in the thickness of cartilage and the thickness of meniscus. Thereby, the difference in the geometry might be an important factor towards the stress deviation.

Moreover, the maximum Von Mises stresses were found to be similar to those reported in literature. Table 2 presents a comparison between our results and results of previous FEA studies. Similar to other studies $(62,89,90)$, the cartilage stress in the medial compartment was found to be larger than that in the lateral compartment, which corresponds to clinical findings showing a greater prevalence of medial OA (94). Hence, the consistency between the results as to shear and Von Mises stresses in this work and the ones in the literature demonstrated that the current FE model is able to generate truthful results.

$<$ Table 2 should be around here $>$ 
The second important key finding of this work was that the increase in the HTO correction angle leads to the decrease of stress in the medial compartment and the increase of stress in the lateral compartment. Thus, previous to the investigation of varying the correction angle on the stress distribution, it is important to clarify that the correction angle is different to the HKA angle used in the clinical area. The correction angle referred to the amount of valgus correction degree, while the HKA angle referred to the Hip-Knee-Ankle alignment. In the conventional HTO surgery, the principal target of alignment is referred to the HKA angle since the amount of correction varies from patient to patient. However, in this work, the correction angle was used for biomechanical analysis to merely investigate the effect of changing the correction angle on the stress distribution of the knee joint.

As the shear stress is commonly considered one of the major risks of accelerating the degeneration of cartilage (95), the peak overall shear stresses of each model were calculated to realize if the shifted loading axis has some effect on the decrease in shear stress in the medial compartment.

A smaller amplitude difference between medial stress decrease and lateral stress increase was derived from the larger reduction of shear stress in the medial compartment, which could explain why knee OA occurs more frequently on the medial compartment of the knee than on the lateral compartment (96).

Another key finding of this work revealed that a balanced stress distribution between two compartments was achieved when the tibia was cut by $16.5^{\circ}$, which is equivalent to a hypercorrection of $4.5^{\circ}$. This finding might contribute to the decision of choosing the optimal correction angle during HTO surgery, since it allows straightening the mechanical axis deformity of the lower limb and brings the knee back to its normal state. In fact, the experimental study of Hernigou et al. (97) showed that all patients who remained within a range of 3 to $6^{\circ}$ were relieved of symptoms after 10 years. Beyond $6^{\circ}$, there were found degradations of the external joint space. This was also the conclusion of the SOFCOT Symposium in 1991. Furthermore, large amount of clinical studies recommended different HKA alignment, varying from $2^{\circ}$ valgus up to $8^{\circ}$ valgus $(2,5,98-101)$. The possible reasons that give rise to such debatable issues may be due to the different surgical techniques, the population and the statistical analysis used in these distinct studies. More importantly, the patient's variability rises as another possible reason for this controversial angle recommendation.

Ultimately, the purpose of the osteotomy surgery is to change the alignment of the knee so that the weight-bearing part of the knee is shifted off the diseased or deformed cartilage in the medial compartment to healthier tissue in the lateral compartment in order to relieve pain and 
increase knee stability. This surgery reduces the progression of OA and consequently, stave off total joint replacement. This clinical objective was well proved by the numerical results of this study. Therefore, the results of this study provide certain biomechanical insights into the evaluation of an optimal correction angle during HTO treatment in terms of stress redistribution.

Regrettably, limited studies were focused on the actual intra-articular effect of an osteotomy, which was target to shift the loading axis from varus to valgus. The only related study, by Yang et al. (83), was to investigate the effect of the frontal plane HKA angle on the stress and strain distributions at the knee cartilage, which developed three FE knee joint models for three individuals. Their results revealed a lower stress in the medial compartment of the varus aligned knee joint compared with the one calculated in the same compartment of both valgus and normal aligned knee joint.

Compared to the study of Yang et al. (83), the results obtained from the current study limited the investigation only into the effect of changing correction angle on the stress distribution in the knee joint, which seemed a more specific and effective method for the simulation of HTO treatment.

Despite the lack of biomechanical evidence to rigorously define the optimal correction angle in an individual patient, this work was carried out to give a more direct way to investigate the alignment optimization by analyzing the stress distribution in the knee joint. Presumably, the appropriate correction depends on the accurate hypercorrection (minimum) necessary to achieve unloading in medial compartment and prevent recurrence of varus deformity. Consequently, avoiding overloading on lateral compartment cartilage by excessive valgus.

The main limitation of the present work is the use of a geometry of a knee model artificially created and not the one specifically developed for a pathological knee. Our study was conducted by considering the knee model in full extension and under one axial force, and therefore, we did not study the dynamic behavior of the model when it is loaded by a gait cycle. Another limitation resides on neglecting the concellous bone and the muscle forces, which could play an important role on the biomechanics of the knee joint during the functional activities. Therefore, considering both the magnitude of the net knee joint loading and the location of the applied muscle forces would increase the overall stress magnitudes on the cartilage and menisci, which might change the patterns of the stress distribution. Moreover, all the knee components were considered as linearly homogenous isotropic material. However, the non-linear behavior of the menisci and the hyperelastic behavior of the ligaments in FEA would lead to more important results, which is promising for the future researches. Additionally, the effect of the mesh refinement in the FE model should also be investigated. 
Finally, in order to clinically validate the results obtained in the determination of the optimal HTO correction angle, it is important to apply the methodology described in this article to support the treatment of real patients and monitor the quality of their recovery.

\section{Acknowledgements}

Authors gratefully acknowledge the funding of Project NORTE-01-0145-FEDER-000022 SciTech - Science and Technology for Competitive and Sustainable Industries, co-financed by "Programa Operacional Regional do Norte" (NORTE2020), through "Fundo Europeu de Desenvolvimento Regional" (FEDER). The authors are also grateful to the Ministry of Higher Education and Scientific Research in Tunisia for the funds provided to conduct the project of the biomechanical modeling of the HTO: Problem of cartilage destruction, grant number: 18PJEC12-14.

\section{References}

1. Heijink A, Gomoll AH, Madry H, et al. Biomechanical considerations in the pathogenesis of osteoarthritis of the knee. Knee Surgery, Sport Traumatol Arthrosc. Springer 2012;20(3):423-35.

2. Schallberger A, Jacobi $M$, Wahl $P$, et al. High tibial valgus osteotomy in unicompartmental medial osteoarthritis of the knee: a retrospective follow-up study over 13-21 years. Knee surgery, Sport Traumatol Arthrosc. Springer 2011;19(1):122-7.

3. Langlais F and Thomazeau H. Ostéotomies du tibia proximal. Tec Chir Traumatol Encycl Med Chir Elsevier, Paris 1999;44-830.

4. Docteur Pierre-Marie JUGNET. L'ostéotomie tibiale de valgisation [Internet]. 2010. Available from: http:/www.chirurgie-orthopedique-nice.com/

5. Sprenger TR and Doerzbacher JF. Tibial osteotomy for the treatment of varus gonarthrosis. J Bone Jt Surg Am. The American Orthopedic Association 2003;85(3):46974.

6. Aglietti P, Buzzi R, Vena LM, et al. High tibial valgus osteotomy for medial gonarthrosis: a 10-to 21-year study. J Knee Surg 2003;16(1):21-6.

7. Valenti JR, Calvo R, Lopez R, et al. Long term evaluation of high tibial valgus osteotomy. Int Orthop. Springer 1990;14(4):347-9.

8. Hernigou PH, Medevielle D, Debeyre J, et al. Proximal tibial osteotomy for osteoarthritis with varus deformity. A ten to thirteen-year follow-up study. J Bone Joint Surg Am 1987;69(3):332-54.

9. Ivarsson I, Myrnerts R and Gillquist J. High tibial osteotomy for medial osteoarthritis of the knee. A 5 to 7 and 11 year follow-up. Bone Joint J. Bone and Joint Journal 1990;72(2):238-44. 
10. Benzakour T, Hefti A, Lemseffer M, et al. High tibial osteotomy for medial osteoarthritis of the knee: 15 years follow-up. Int Orthop. Springer 2010;34(2):209-15.

11. Mina C, Garrett WE, Pietrobon R, et al. High tibial osteotomy for unloading osteochondral defects in the medial compartment of the knee. Am J Sports Med. American Orthopaedic Society for Sports Medicine 2008;36(5):949-55.

12. Briem K, Ramsey DK, Newcomb W, et al. Effects of the amount of valgus correction for medial compartment knee osteoarthritis on clinical outcome, knee kinetics and muscle co-contraction after opening wedge high tibial osteotomy. J Orthop Res. Wiley Online Library 2007;25(3):311-8.

13. Narang YS, Arelekatti VNM and Winter AG. The effects of the inertial properties of above-knee prostheses on optimal stiffness, damping, and engagement parameters of passive prosthetic knees. J Biomech Eng. American Society of Mechanical Engineers 2016;138(12):121002.

14. Fujie H, Sekito $\mathrm{T}$ and Orita A. A novel robotic system for joint biomechanical tests: application to the human knee joint. Trans Soc Mech Eng J Biomech Eng. american society mechanical engineers 2004;126(1):54-61.

15. Leatherman ER, Guo H, Gilbert SL, et al. Using a statistically calibrated biphasic finite element model of the human knee joint to identify robust designs for a meniscal substitute. $J$ Biomech Eng. American Society of Mechanical Engineers 2014;136(7):71007.

16. Venäläinen MS, Mononen ME, Jurvelin JS, et al. Importance of material properties and porosity of bone on mechanical response of articular cartilage in human knee joint - a two-dimensional finite element study. J Biomech Eng. American Society of Mechanical Engineers 2014;136(12):121005.

17. Halonen KS, Mononen ME, Jurvelin JS, et al. Importance of patella, quadriceps forces, and depthwise cartilage structure on knee joint motion and cartilage response during gait. J Biomech Eng. American Society of Mechanical Engineers 2016;138(7):71002.

18. Blankevoort L and Huiskes R. Validation of a three-dimensional model of the knee. $J$ Biomech. Elsevier 1996;29(7):955-61.

19. Blankevoort L, Kuiper JH, Huiskes R, et al. Articular contact in a three-dimensional model of the knee. J Biomech. Elsevier 1991;24(11):1019-31.

20. Brown TD and DiGioia AM. A contact-coupled finite element analysis of the natural adult hip. J Biomech. Elsevier 1984;17(6):437-48.

21. Butler DL, Kay MD and Stouffer DC. Comparison of material properties in fasciclebone units from human patellar tendon and knee ligaments. $J$ Biomech. Elsevier 1986;19(6):425-32.

22. Clark AL, Barclay LD, Matyas JR, et al. In situ chondrocyte deformation with physiological compression of the feline patellofemoral joint. $J$ Biomech. Elsevier 2003;36(4):553-68.

23. Coles JM, Blum JJ, Jay GD, et al. In situ friction measurement on murine cartilage by atomic force microscopy. J Biomech. Elsevier 2008;41(3):541-8.

24. Crolet JM, Aoubiza B and Meunier A. Compact bone: numerical simulation of 
mechanical characteristics. J Biomech. Elsevier 1993;26(6):677-87.

25. Crowninshield R, Pope MH and Johnson RJ. An analytical model of the knee. J Biomech. Elsevier 1976;9(6):397-405.

26. Currey JD. The many adaptations of bone. J Biomech. Elsevier 2003;36(10):1487-95.

27. Dalstra M, Huiskes R, Odgaard A, et al. Mechanical and textural properties of pelvic trabecular bone. J Biomech. Elsevier 1993;26(4-5):523-35.

28. Dalstra M and Huiskes R. Load transfer across the pelvic bone. J Biomech. Elsevier 1995;28(6):715-24.

29. Dalstra M, Huiskes R and Van Erning L. Development and validation of a threedimensional finite element model of the pelvic bone. J Biomech Eng. American Society of Mechanical Engineers 1995;117(3):272-8.

30. DeFrate LE, Sun H, Gill TJ, et al. In vivo tibiofemoral contact analysis using 3D MRIbased knee models. J Biomech. Elsevier 2004;37(10):1499-504.

31. Donahue TLH, Hull ML, Rashid MM, et al. How the stiffness of meniscal attachments and meniscal material properties affect tibio-femoral contact pressure computed using a validated finite element model of the human knee joint. $J$ Biomech. Elsevier 2003;36(1):19-34.

32. Donahue TLH, Hull ML, Rashid MM, et al. A finite element model of the human knee joint for the study of tibio-femoral contact. J Biomech Eng. American Society of Mechanical Engineers 2002;124(3):273-80.

33. Donzelli PS, Spilker RL, Ateshian GA, et al. Contact analysis of biphasic transversely isotropic cartilage layers and correlations with tissue failure. $J$ Biomech. Elsevier 1999;32(10):1037-47.

34. Duda GN, Heller M, Albinger J, et al. Influence of muscle forces on femoral strain distribution. J Biomech. Elsevier 1998;31(9):841-6.

35. Duda GN, Mandruzzato F, Heller M, et al. Mechanical boundary conditions of fracture healing: borderline indications in the treatment of unreamed tibial nailing. J Biomech. Elsevier 2001;34(5):639-50.

36. Erdemir A, McLean S, Herzog W, et al. Model-based estimation of muscle forces exerted during movements. Clin Biomech. Elsevier 2007;22(2):131-54.

37. Erdemir A, Viveiros ML, Ulbrecht JS, et al. An inverse finite-element model of heel-pad indentation. J Biomech. Elsevier 2006;39(7):1279-86.

38. Garg A and Walker PS. Prediction of total knee motion using a three-dimensional computer-graphics model. J Biomech. Elsevier 1990;23(1):45-58.

39. Halloran JP, Ackermann M, Erdemir A, et al. Concurrent musculoskeletal dynamics and finite element analysis predicts altered gait patterns to reduce foot tissue loading. $J$ Biomech. Elsevier 2010;43(14):2810-5.

40. Herzog W, Diet S, Suter E, et al. Material and functional properties of articular cartilage and patellofemoral contact mechanics in an experimental model of osteoarthritis. $J$ Biomech. Elsevier 1998;31(12):1137-45. 
41. Hirokawa S and Tsuruno R. Three-dimensional deformation and stress distribution in an analytical/computational model of the anterior cruciate ligament. $J$ Biomech. Elsevier 2000;33(9):1069-77.

42. Trad Z, Barkaoui A and Chafra M. A Three Dimensional Finite Element Analysis of Mechanical Stresses in the Human Knee Joint: Problem of Cartilage DestructionA Three Dimensional Finite Element Analysis of Mechanical Stresses in the Human Knee Joint: Problem of Cartilage Destruction. Journal of Biomimetics, Biomaterials and Biomedical Engineering. Trans Tech Publ 2017. p. 29-39.

43. Scotti $\mathrm{C}$, Hirschmann $\mathrm{M}$, Antinolfi $\mathrm{P}$, et al. Meniscus repair and regeneration: review on current methods and research potential. Eur Cell Mater. European Cells \& Materials 2013;26:150-70.

44. Sahu NK and Kaviti AK. A Review of Use FEM Techniques in Modeling of Human Knee Joint. Journal of Biomimetics, Biomaterials and Biomedical Engineering. Trans Tech Publ 2016. p. 14-25.

45. Moran CJ, Busilacchi A, Lee CA, et al. Biological augmentation and tissue engineering approaches in meniscus surgery. Arthroscopy. Elsevier 2015;31(5):944-55.

46. Makris EA, Hadidi P and Athanasiou KA. The knee meniscus: structure-function, pathophysiology, current repair techniques, and prospects for regeneration. Biomaterials. Elsevier 2011;32(30):7411-31.

47. Trad Z, Barkaoui A, Chafra M, et al. FEM Analysis of the Human Knee Joint: A Review. Springer, Cham; 2018.

48. Fernandes DJC. Finite Element Analysis of the ACL-deficient Knee. 2014.

49. Pena E, Calvo B, Martinez MA, et al. A three-dimensional finite element analysis of the combined behavior of ligaments and menisci in the healthy human knee joint. J Biomech. Elsevier 2006;39(9):1686-701.

50. Pena E, Calvo B, Martinez MA, et al. Finite element analysis of the effect of meniscal tears and meniscectomies on human knee biomechanics. Clin Biomech. Elsevier 2005;20(5):498-507.

51. Pena E, Martinez MA, Calvo B, et al. A finite element simulation of the effect of graft stiffness and graft tensioning in ACL reconstruction. Clin Biomech. Elsevier 2005;20(6):636-44.

52. Peña E, Calvo B, Martínez MA, et al. Computer simulation of damage on distal femoral articular cartilage after meniscectomies. Comput Biol Med. Elsevier 2008;38(1):69-81.

53. Peña E, Calvo B, Martínez MA, et al. Effect of the size and location of osteochondral defects in degenerative arthritis. A finite element simulation. Comput Biol Med. Elsevier 2007;37(3):376-87.

54. Peña E, Calvo B, Martinez MA, et al. Why lateral meniscectomy is more dangerous than medial meniscectomy. A finite element study. J Orthop Res. Wiley Online Library 2006;24(5):1001-10.

55. Halonen KS, Mononen ME, Jurvelin JS, et al. Importance of depth-wise distribution of collagen and proteoglycans in articular cartilage - a 3D finite element study of stresses and strains in human knee joint. J Biomech. Elsevier 2013;46(6):1184-92. 
56. Guess TM, Thiagarajan G, Kia M, et al A subject specific multibody model of the knee with menisci. Med Eng Phys. Elsevier 2010;32(5):505-15.

57. Łuczkiewicz P, Daszkiewicz K, Chróścielewski J, et al. The Influence of Articular Cartilage Thickness Reduction on Meniscus Biomechanics. PLoS One. Public Library of Science 2016;11(12):e0167733.

58. Russell ME, Shivanna KH, Grosland NM, et al. Cartilage contact pressure elevations in dysplastic hips: a chronic overload model. J Orthop Surg Res. BioMed Central 2006;1(1):1.

59. Bachtar F, Chen X and Hisada T. Finite element contact analysis of the hip joint. Med Biol Eng Comput. Springer 2006;44(8):643-51.

60. Izaham RMAR, Kadir MRA, Rashid AHA, et al. Finite element analysis of Puddu and Tomofix plate fixation for open wedge high tibial osteotomy. Injury. Elsevier 2012;43(6):898-902.

61. Harris MD, Anderson AE, Henak CR, et al. Finite element prediction of cartilage contact stresses in normal human hips. J Orthop Res. Wiley Online Library 2012;30(7):1133-9.

62. Zheng KK, Chen JN, Scholes C, et al. Magnetic Resonance Imaging (MRI) Based Finite Element Modeling for Analyzing the Influence of Material Properties on Menisci Responses. Applied Mechanics and Materials. Trans Tech Publ 2014. p. 305-9.

63. Rho JY, Ashman RB and Turner CH. Young's modulus of trabecular and cortical bone material: ultrasonic and microtensile measurements. $J$ Biomech. Elsevier 1993;26(2):111-9.

64. Wang Y, Fan Y and Zhang M. Comparison of stress on knee cartilage during kneeling and standing using finite element models. Med Eng Phys. Elsevier 2014;36(4):439-47.

65. Zielinska B and Donahue TLH. 3D finite element model of meniscectomy: changes in joint contact behavior. J Biomech Eng. American Society of Mechanical Engineers 2006;128(1):115-23.

66. Zysset PK, Guo XE, Hoffler CE, et al. Elastic modulus and hardness of cortical and trabecular bone lamellae measured by nanoindentation in the human femur. J Biomech. Elsevier 1999;32(10):1005-12.

67. Kempson GE. The mechanical properties of articular cartilage. The joints and synovial fluid. Academic Press New York 1980;2:177-238.

68. Li G, Gil J, Kanamori A, et al. A validated three-dimensional computational model of a human knee joint. J Biomech Eng. American Society of Mechanical Engineers 1999;121(6):657-62.

69. Li G, Orlando L and Harry H. Variability of a Three Dimensional Finite Element Model Constructed Using Magnetic Resonance Images of a Knee for Joint Contact Stress Analysis. J Biomech Eng Asme 2001;123(4):341-6.

70. Li G, Lopez O and Rubash H. Variability of a three-dimensional finite element model constructed using magnetic resonance images of a knee for joint contact stress analysis. J Biomech Eng. American Society of Mechanical Engineers 2001;123(4):341-6.

71. Li G, Suggs J and Gill T. The effect of anterior cruciate ligament injury on knee joint function under a simulated muscle load: a three-dimensional computational simulation. 
Ann Biomed Eng. Springer 2002;30(5):713-20.

72. Mommersteeg TJA, Huiskes R, Blankevoort L, et al. A global verification study of a quasi-static knee model with multi-bundle ligaments. $J$ Biomech. Elsevier 1996;29(12):1659-64.

73. Mow VC, Lai WM and Holmes MH. Advanced theoretical and experimental techniques in cartilage research. Biomechanics: Principles and applications. Springer 1982. p. 4774.

74. Armstrong CG, Mow VC and Wirth CR. Biomechanics of impact-induced microdamage to articular cartilage: a possible genesis for chondromalacia patella. AAOS Symposium on Sports Medicine: the Knee CV Mosby Co, St Louis 1985. p. 70-84.

75. Beillas P, Papaioannou G, Tashman S, et al. A new method to investigate in vivo knee behavior using a finite element model of the lower limb. J Biomech. Elsevier 2004;37(7):1019-30.

76. Bendjaballah MZ, Shirazi-Adl A and Zukor DJ. Biomechanics of the human knee joint in compression: reconstruction, mesh generation and finite element analysis. knee. Elsevier 1995;2(2):69-79.

77. Kiapour AM, Kaul V, Kiapour A, et al. The effect of ligament modeling technique on knee joint kinematics: a finite element study. Appl Math. NIH Public Access 2014;4(5A):91.

78. Penrose JMT, Holt GM, Beaugonin M, et al. Development of an accurate threedimensional finite element knee model. Comput Methods Biomech Biomed Eng. Taylor \& Francis 2002;5(4):291-300.

79. Ramaniraka NA, Saunier P and Siegrist O. Effects of intra-articular and extra-articular procedures in anterior cruciate ligament (ACL) reconstruction. Comput Methods Biomech Biomed Engin. Taylor \& Francis 2005;8(S1):231-2.

80. Ramaniraka NA, Saunier P, Siegrist O, et al. Biomechanical evaluation of intra-articular and extra-articular procedures in anterior cruciate ligament reconstruction: a finite element analysis. Clin Biomech. Elsevier 2007;22(3):336-43.

81. Wan C, Hao Z and Wen S. The effect of the variation in ACL constitutive model on joint kinematics and biomechanics under different loads: a finite element study. $J$ Biomech Eng. American Society of Mechanical Engineers 2013;135(4):41002.

82. LeRoux MA and Setton LA. Experimental and biphasic FEM determinations of the material properties and hydraulic permeability of the meniscus in tension. $J$ Biomech Eng. American Society of Mechanical Engineers 2002;124(3):315-21.

83. Yang NH, Nayeb-Hashemi H, Canavan PK, et al. Effect of frontal plane tibiofemoral angle on the stress and strain at the knee cartilage during the stance phase of gait. $J$ Orthop Res. Wiley Online Library 2010;28(12):1539-47.

84. Hsu RW, Himeno S, Coventry MB, et al. Normal axial alignment of the lower extremity and load-bearing distribution at the knee. Clin Orthop Relat Res. LWW 1990;255:21527.

85. Coventry MB. Upper tibial osteotomy. Clin Orthop Relat Res. LWW 1984;182:46-52.

86. Birmingham TB, Giffin JR, Chesworth BM, et al. Medial opening wedge high tibial 
osteotomy: A prospective cohort study of gait, radiographic, and patient-reported outcomes. Arthritis Care Res (Hoboken). Wiley Online Library 2009;61(5):648-57.

87. Benzakour T, Hefti A, Lemseffer M, et al. Int Orthop. Springer 2010;34(2):209-15.

88. Walker PS and Erkiuan MJ. The role of the menisci in force transmission across the knee. Clin Orthop Relat Res. LWW 1975;109:184-92.

89. Zheng K. The Effect of High Tibial Osteotomy Correction Angle on Cartilage and Meniscus Loading Using Finite Element Analysis. PhD Thesis, University of Sydney, Australia; 2014.

90. Zhu G-D, Guo W-S, Zhang Q-D, et al. Finite Element Analysis of Mobile-bearing Unicompartmental Knee Arthroplasty: The Influence of Tibial Component Coronal Alignment. Chin Med J (Engl). Medknow Publications 2015;128(21):2873.

91. Papaioannou G, Demetropoulos CK and King YH. Predicting the effects of knee focal articular surface injury with a patient-specific finite element model. Knee. Elsevier 2010;17(1):61-8.

92. Yang NH, Canavan PK, Nayeb-Hashemi H, et al. Protocol for constructing subjectspecific biomechanical models of knee joint. Comput Methods Biomech Biomed Engin. Taylor \& Francis 2010;13(5):589-603.

93. Gardiner JC and Weiss JA. Subject-specific finite element analysis of the human medial collateral ligament during valgus knee loading. J Orthop Res. Wiley Online Library 2003;21(6):1098-106.

94. Jackson BD, Wluka AE, Teichtahl AJ, et al. Reviewing knee osteoarthritis - a biomechanical perspective. J Sci Med Sport. Elsevier 2004;7(3):347-57.

95. Riegger-Krugh C, Gerhart TN, Powers WR, et al. Tibiofemoral contact pressures in degenerative joint disease. Clin Orthop Relat Res. LWW 1998;348:233-45.

96. Sharma L, Song J, Felson DT, et al. The role of knee alignment in disease progression and functional decline in knee osteoarthritis. Jama. American Medical Association 2001;286(2):188-95.

97. Hernigou P, Ovadia $\mathrm{H}$ and Goutallier D. Modélisation mathématique de l'ostéotomie tibiale d'ouverture et tables de correction. Rev Chir Orthop Reparatrice Appar Mot. Masson 1992;78(4):258-63.

98. Korovessis P, Katsoudas G, Salonikides P, et al. Medium-and long-term results of high tibial osteotomy for varus gonarthrosis in an agricultural population. Orthopedics. SLACK Incorporated 1999;22(8):729-35.

99. Magyar G, Toksvig-Larsen S and Lindstrand A. Open wedge tibial osteotomy by callus distraction in gonarthrosis: operative technique and early results in 36 patients. Acta Orthop Scand. Taylor \& Francis 1998;69(2):147-51.

100. Koshino T, Yoshida T, Ara Y, et al. Fifteen to twenty-eight years' follow-up results of high tibial valgus osteotomy for osteoarthritic knee. knee. Elsevier 2004;11(6):439-44.

101. Esenkaya I and Elmali N. Proximal tibia medial open-wedge osteotomy using plates with wedges: early results in 58 cases. Knee Surgery, Sport Traumatol Arthrosc. Springer 2006;14(10):955-61. 


\section{FIGURE CAPTIONS}

Figure 1 - Design of the human knee joint (A: anterior view, B: posterior view).

Figure 2 - Finite element model built of the knee joint (1: femoral cartilage, 2: external and internal meniscus, 3: tibial cartilage on both medial and lateral sides).

Figure 3 - Loads and Boundary conditions assigned to the knee joint model.

Figure 4 - Knee model with a varus deformity of $12^{\circ}$.

Figure 5 - Bone resection technique and the different correction angles studied by FE modeling. Figure 6 - Example of the different steps of the HTO modeling for a correction angle of $15^{\circ}$.

Figure 7 - A real femoral cartilage and the stress distribution obtained in the modeled articular cartilage by $\quad$ FE $\quad$ simulation (real image from http://www.drballester.com/lesiondelcartilagodelarodilla.html).

Figure 8 - Variation of the maximum Von Mises stresses in femoral and tibial cartilage of both compartments across the change of valgus correction.

Figure 9 - Variation of maximum shear stresses in femoral and tibial cartilage of both compartments across the change of valgus correction.

Figure 10 - Stress distribution in the articular cartilages on the healthy knee model and in pre and post-operative. 


\section{FIGURES}

Figure 1

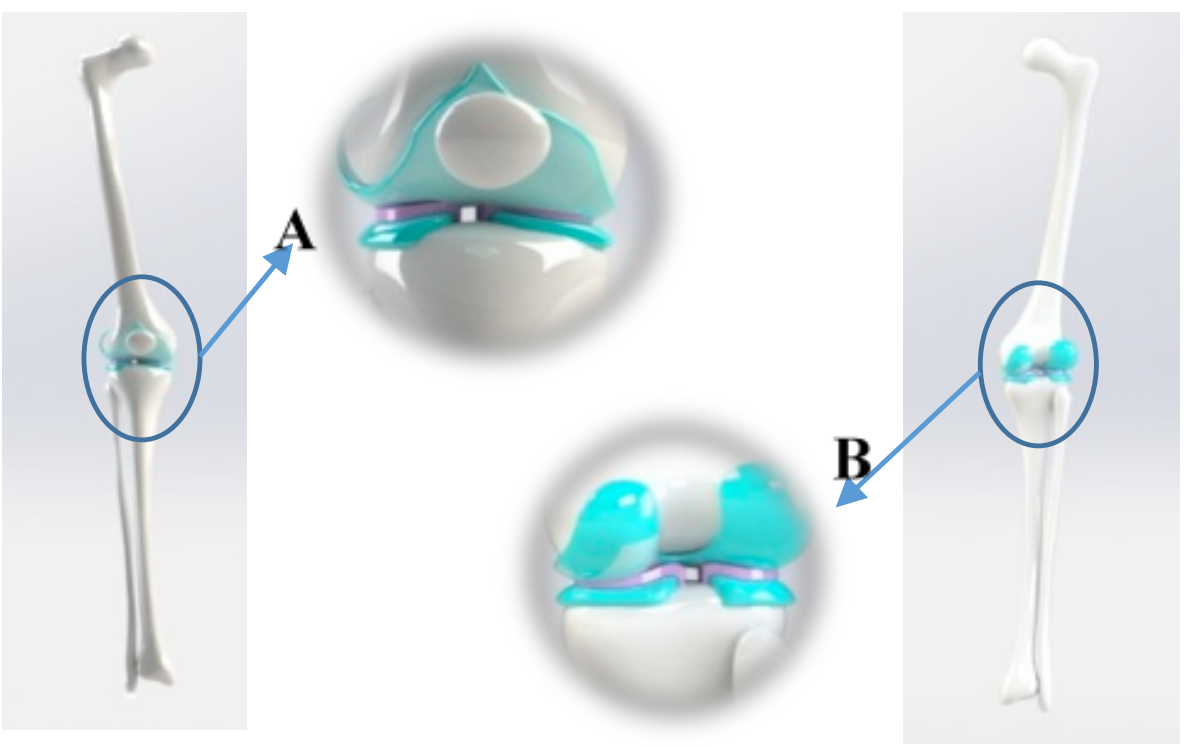

Figure 2

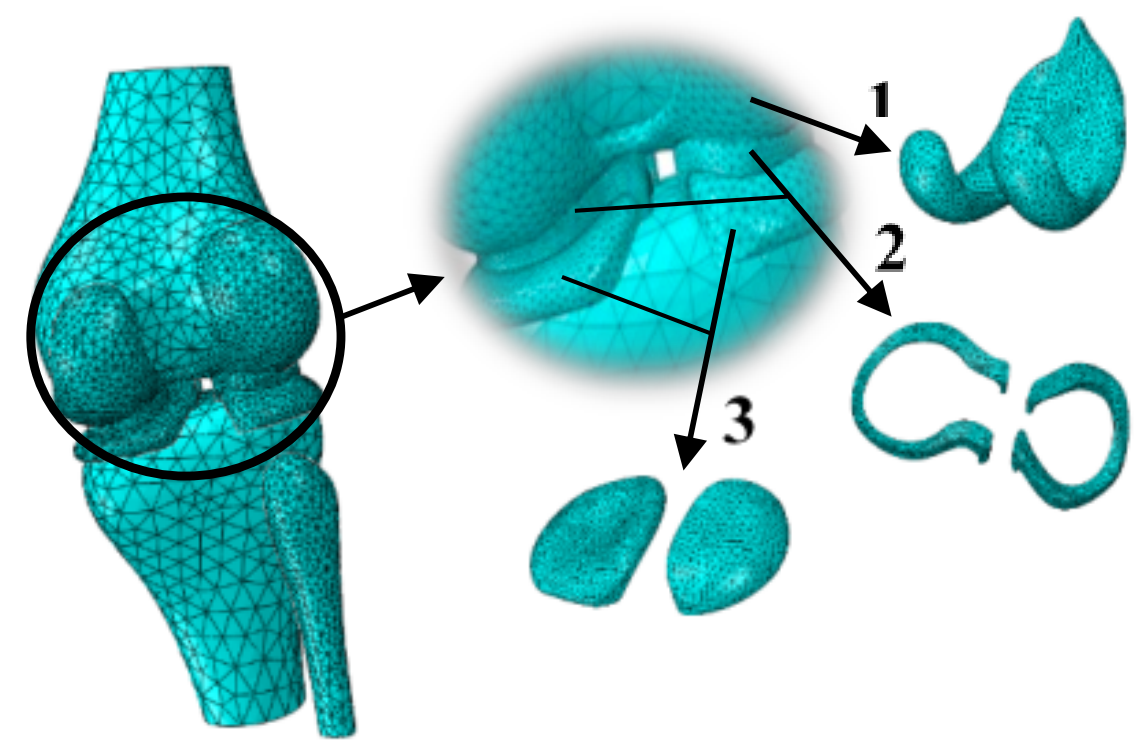


Figure 3

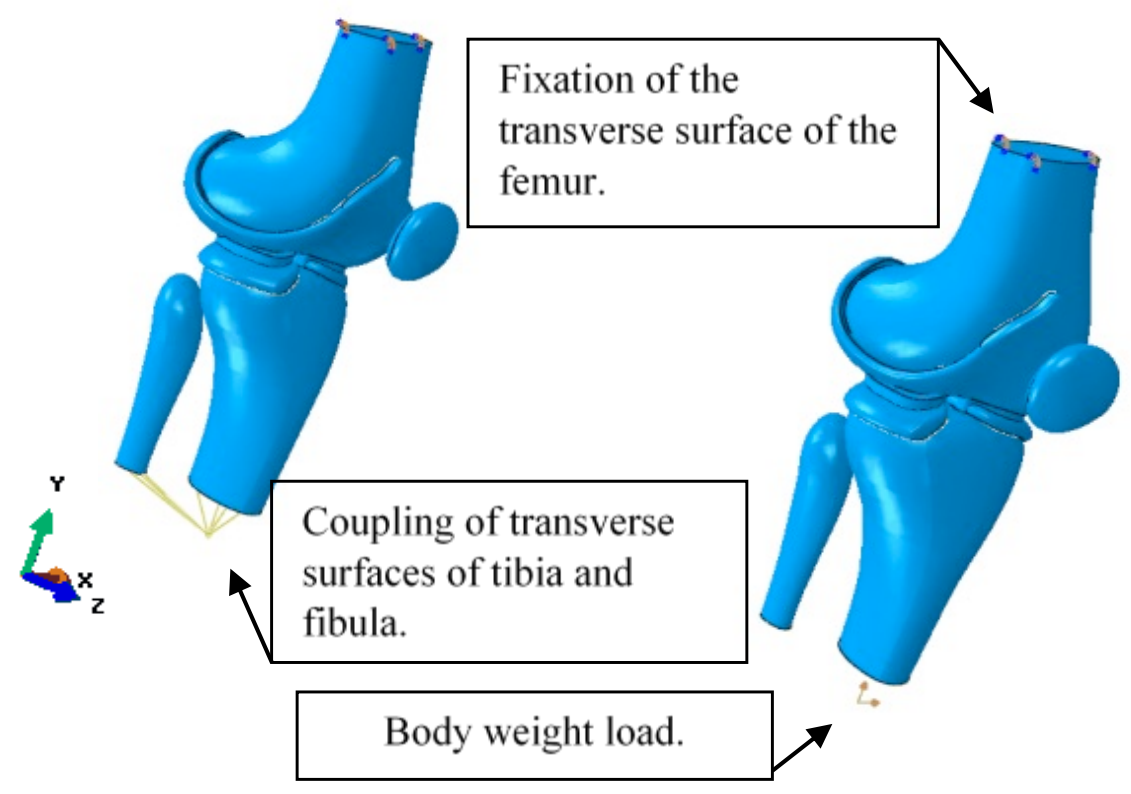

Figure 4

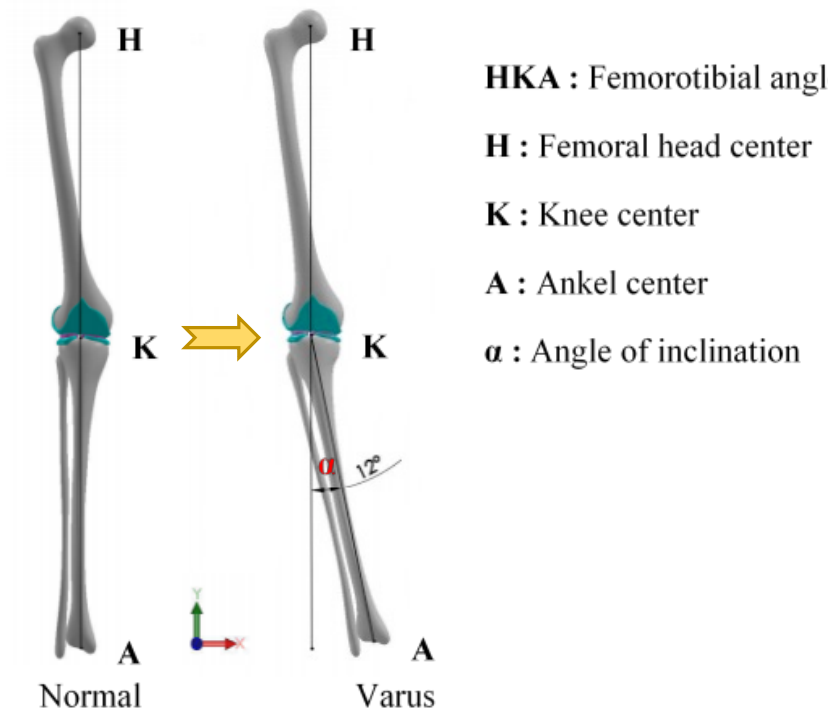

HKA $=180^{\circ}$

HKA $=168^{\circ}$ 
Figure 5

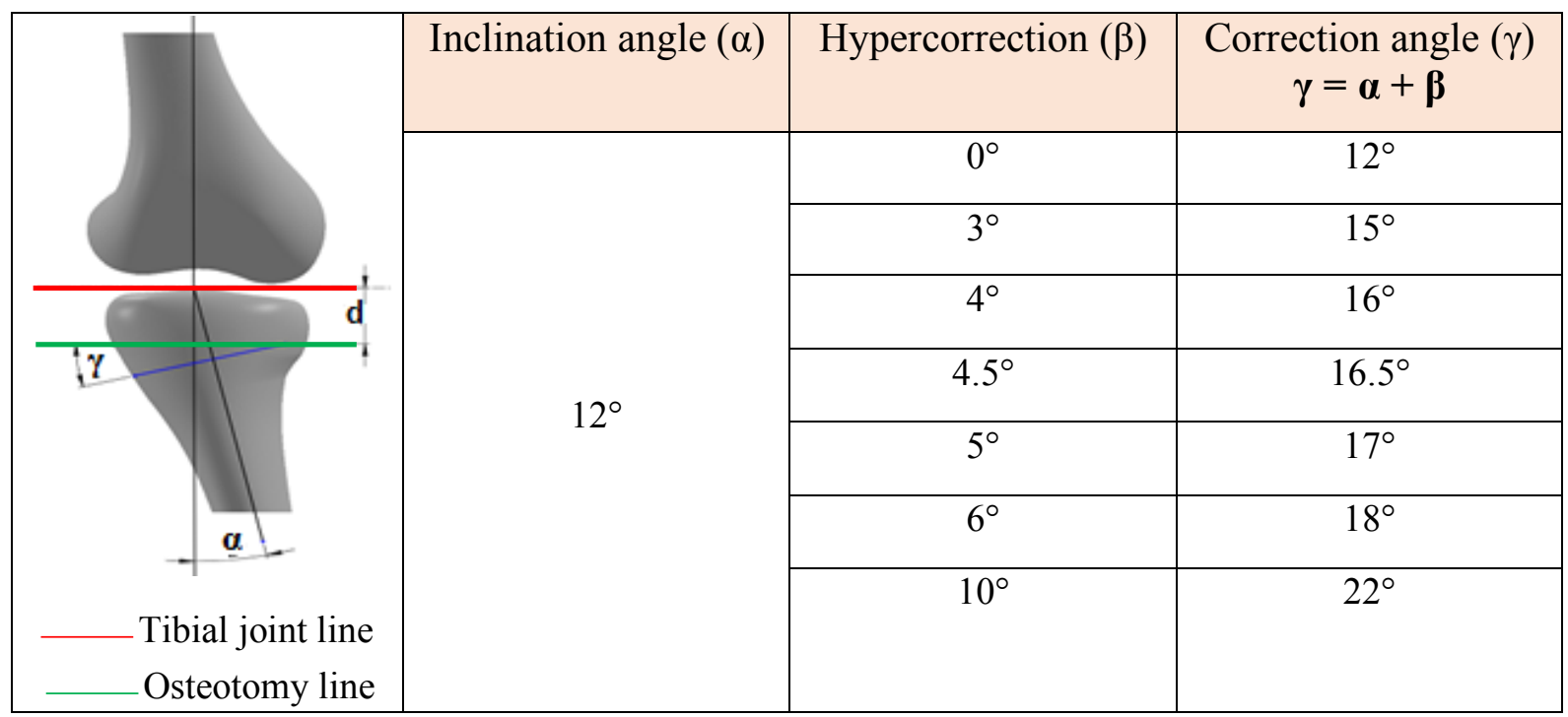


Figure 6
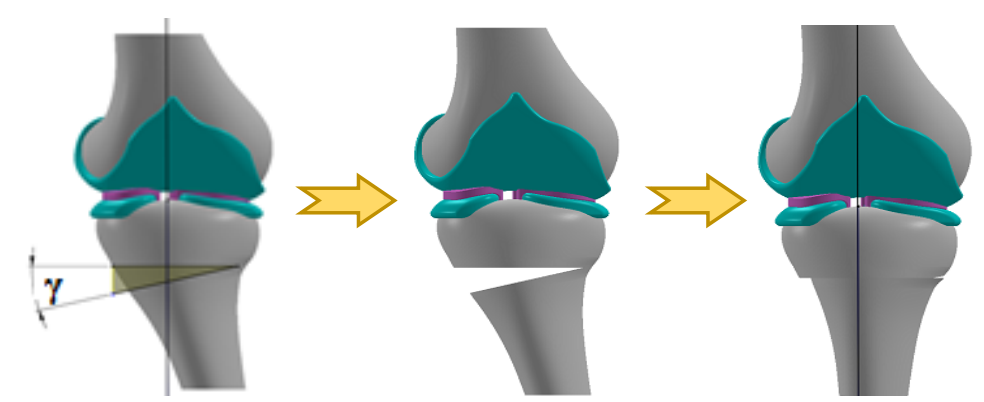

1: Preparation of the correction angle $(\gamma)$

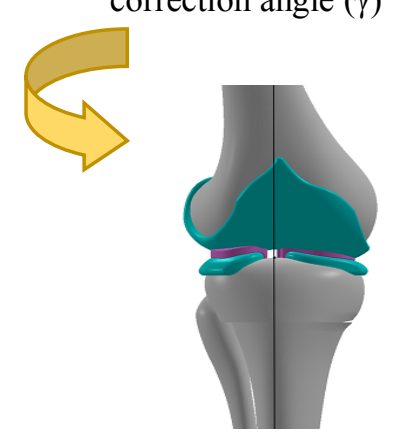

2 : Removal of the tibia bone

3 : Closure of osteotomy

The varus knee of $12^{\circ}$ after HTO

Exporting the model to Abaqus

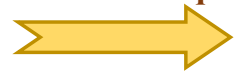

Figure 7

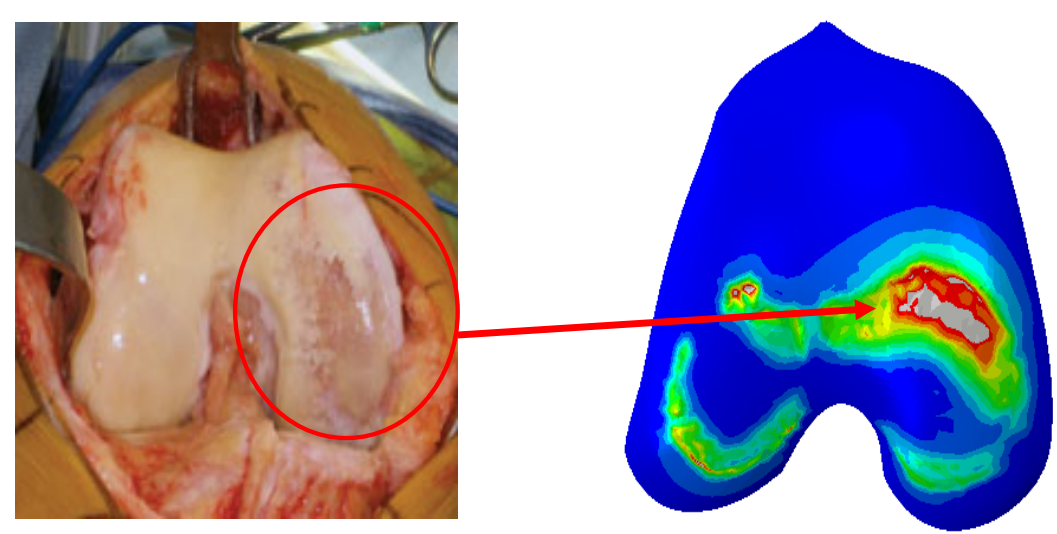


Figure 8
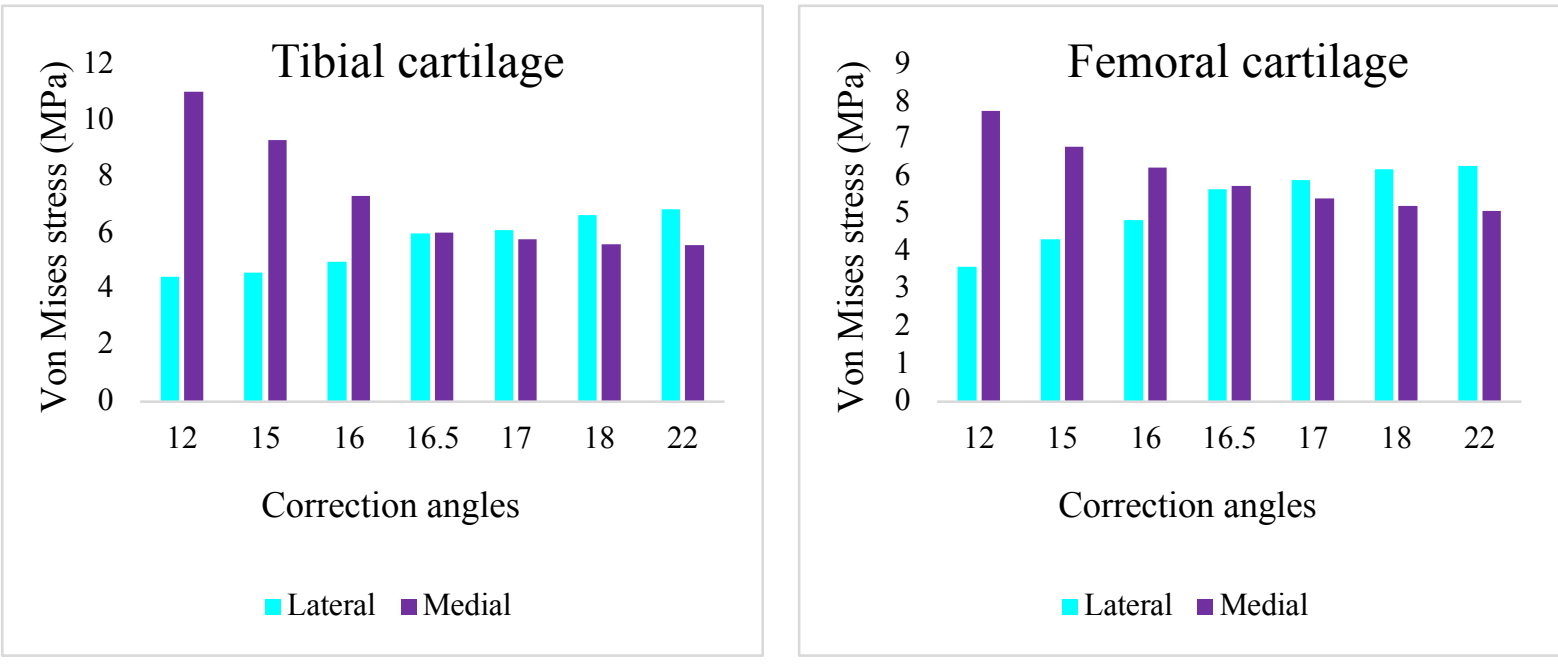

Figure 9
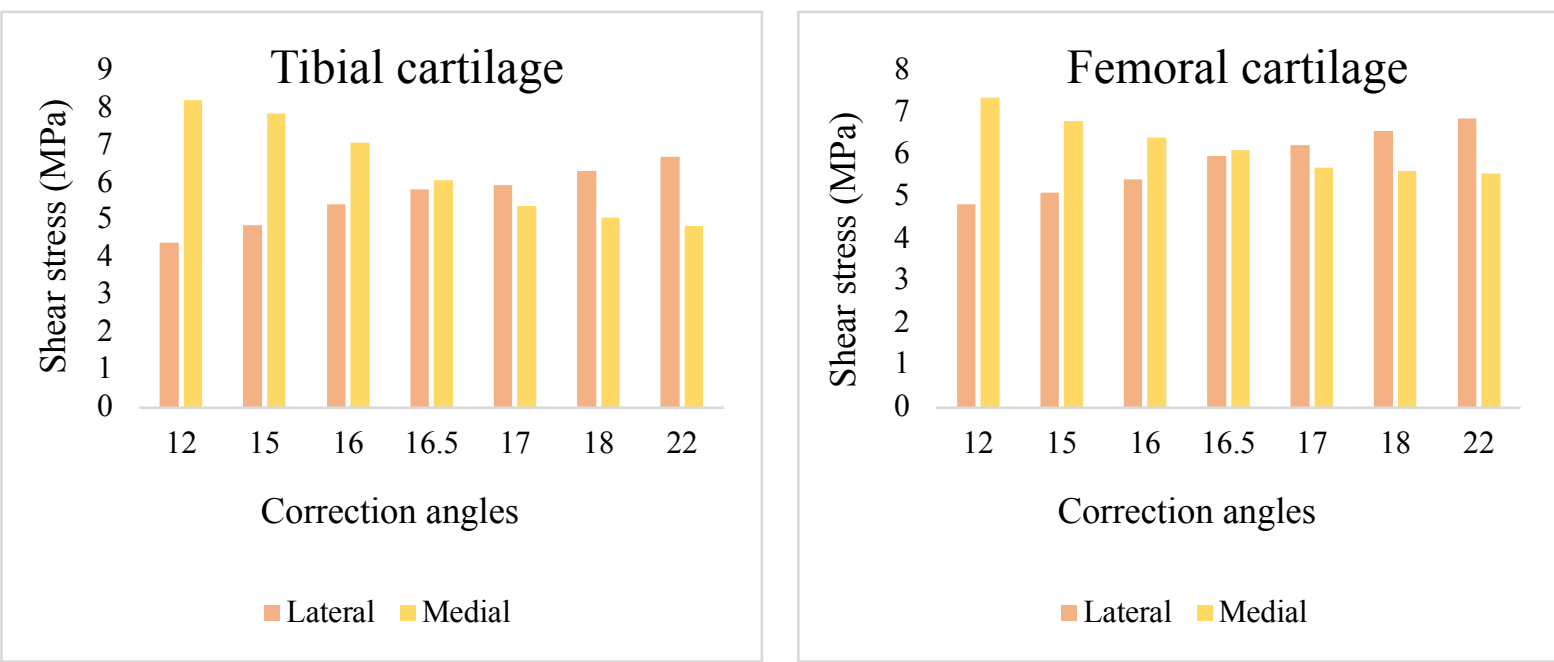
Figure 10

\begin{tabular}{|c|c|c|c|}
\hline Healthy knee & Varus knee before HTO & $\begin{array}{l}\text { Varus knee after HTO } \\
\qquad\left(\beta=4.5^{\circ}\right)\end{array}$ & $\begin{array}{r}\text { Von Mises } \\
(\mathrm{MPa})\end{array}$ \\
\hline & & & 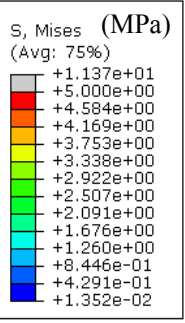 \\
\hline \multicolumn{4}{|c|}{ Medial tibial cartilage } \\
\hline & & & 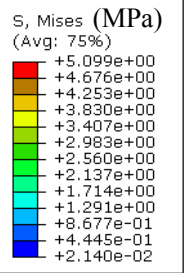 \\
\hline \multicolumn{4}{|c|}{ Lateral tibial cartilage } \\
\hline & & & 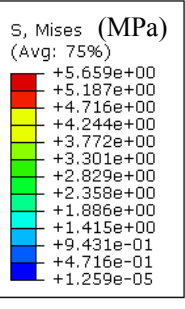 \\
\hline \multicolumn{4}{|c|}{ Femoral cartilage } \\
\hline
\end{tabular}




\section{TABLES CAPTIONS}

Table 1 - Maximum Shear Stresses (MPa) on cartilages and menisci in the healthy knee joint and in pre and postoperative

Table 2 - Comparison between the Von Mises stresses (MPa) obtained in the present study and the ones indicated in the literature 


\section{TABLES}

\section{Table 1}

\begin{tabular}{|lccc|}
\hline \multicolumn{4}{|c|}{ Maximum Shear Stresses (MPa) on cartilages and menisci in the healthy knee joint } \\
$\begin{array}{r}\alpha \text { and in pre and postoperative } \\
\alpha=0^{\circ} \\
\text { (normal knee) }\end{array}$ & $\begin{array}{c}\alpha=12^{\circ} \\
\text { (varus knee) }\end{array}$ & $\begin{array}{c}\alpha=0^{\circ} \text { after HTO } \\
\left(\beta=4.5^{\circ}\right)\end{array}$ \\
\hline Medial Femoral cartilage & 6.1 & 8.67 & 5.76 \\
\hline Lateral Femoral cartilage & 5.34 & 4.27 & 5.67 \\
\hline Medial tibial cartilage & 5.9 & 12.21 & 6.01 \\
\hline Lateral tibial cartilage & 5.46 & 4.8 & 5.6 \\
\hline
\end{tabular}

Table 2

Comparison between the Von Mises stresses ( $\mathrm{MPa}$ ) obtained in the present study and the ones indicated in the literature

\begin{tabular}{lccc} 
& $\begin{array}{c}\text { The present work } \\
(\mathrm{F}=740 \mathrm{~N})\end{array}$ & $\begin{array}{c}\text { The study of Zhu et al.(90) } \\
(\mathrm{F}=1000 \mathrm{~N})\end{array}$ & $\begin{array}{c}\text { The study of Zheng (89) } \\
(\mathrm{F}=740 \mathrm{~N})\end{array}$ \\
\hline Femoral cartilage & 1.75 & - & 1.88 \\
Medial tibial cartilage & 2.65 & 2.68 & \\
Lateral tibial cartilage & 1.93 & 2.43 & 3.06
\end{tabular}

